\title{
PROMOVENDO A “CULTURA DO REINO”: NOTAS SOBRE MÚSICA, RELIGIÃO E CULTURA A PARTIR DE UMA JUVENTUDE EVANGÉLICA NO SUL DO BRASIL ${ }^{1}$
}

\section{Taylor Pedroso de Aguiar ${ }^{2}$}

Resumo: O termo "gospel" tem sido acionado por agentes do meio religioso como um conceito que fortalece determinadas relaçóes entre religião e espaço público no Brasil. No caso evangélico, trata-se de um elemento importante em aproximaçóes com políticas culturais através da música, sendo apresentado enquanto um conceito marcador que refletiria uma "cultura evangélica". Este trabalho se debruça etnograficamente sobre os cultos da Brasa Church - movimento de jovens da Igreja Brasa, em Porto Alegre/RS - e sobre a tendência musical adotada por aquela comunidade evangélica: o worship. À medida que revela uma visáo de igreja específica, a adoraçáo na Brasa Church permite visualizar nuances em torno dos sentidos de "cultura" para os evangélicos. Focalizando as formas que esses sentidos assumem na Brasa Church, pretende-se demonstrar limites quanto a definiçóes genéricas do gospel. Outrossim, procura-se discutir alguns dos contornos da "cultura do Reino" que o worship tem buscado promover.

Palavras-chave: Música Gospel; Cultura Gospel; Brasa Church; Worship.

PROMOTING THE "KINGDOM CULTURE": NOTES ON MUSIC, RELIGION AND CULTURE BASED ON AN EVANGELICAL YOUTH IN SOUTHERN BRAZIL

\begin{abstract}
The term "gospel" has been activated by religious agents as a concept that strengthens certain relations between religion and public space in Brazil. In

1 Como citar: AGUIAR, Taylor Pedroso de. Promovendo a "Cultura do Reino": notas sobre música, religiáo e cultura a partir de uma juventude evangélica no sul do Brasil. Debates do NER, Porto Alegre, v. 1, n. 37, p. 141-167, 2020.

2 Doutorando em Antropologia Social pelo Programa de Pós-Graduaçáo em Antropologia Social da Universidade Federal do Rio Grande do Sul, Porto Alegre, Brasil. E-mail: taylor.aguiar@ufrgs.br.
\end{abstract}

Debates do NER, Porto Alegre, Ano 20, N. 37, P. I 4 I-I67, JAN./JUl. 2020 
the evangelical case, this is an important element in approaching cultural policies through music, when presented as a marker concept that would reflect an "evangelical culture". This work focuses ethnographically on the cults of Brasa Church - the youth movement of the Brasa Church in Porto Alegre/RS - and on the musical tendency adopted by that evangelical community: worship. As it reveals a specific church vision, worship at Brasa Church allows us to visualize nuances around the senses of "culture" for evangelicals. Focusing on the forms that these meanings assume in Brasa Church, it is tried to demonstrate limits on generic definitions of gospel. In addition, we try to discuss some of the contours of the "Kingdom culture" that worship has sought to promote.

Keywords: Gospel Music; Gospel Culture; Brasa Church; Worship.

\section{INTRODUÇÃO}

O que está em jogo quando certos usos e definiçôes da categoria "gospel” são acionados na arena pública, mobilizando agentes religiosos e políticos na esteira de açóes que se relacionam diretamente com o universo evangélico? A despeito dos desafios que se colocam às tentativas de compreensão das relações tramadas entre evangélicos e espaço público no Brasil, acentuados, sobretudo, pelo expressivo crescimento (neo) pentecostal experimentado nas últimas décadas e pela heterogeneidade a partir da qual historicamente se constitui esse campo religioso no país, autores como Almeida (2006), Giumbelli (2008) e Birman (2012), entre outros/as, têm encarado sob diferentes óticas a tarefa de aprofundar pesquisas acerca dessas relações e suas modalidades.

Diversos estudos têm sido realizados no âmbito das ciências sociais no intento de compreender mais claramente o fenômeno da música gospel brasileira $^{3}$. O crescimento evangélico das últimas décadas, ao suscitar discussões em torno dos novos e variados lugares assumidos por esse segmento

\footnotetext{
${ }^{3}$ Para uma revisão bibliográfica mais atualizada sobre o tema, ver Bandeira (2017a).
} 
religioso na sociedade, passou a demandar a articulação de pesquisas que acompanhassem o desdobramento de suas relaçóes com o espaço público, a política e as mídias, entre outras intersecçôes possíveis. Na senda das reflexôes que acompanham este debate está incluído o desenvolvimento do conceito de "cultura gospel", tomado como um marcador da música evangélica e de seu mercado e nicho midiático. Atrelado ao gospel, o conceito de "cultura" chama a atençâo por ser um mediador produtivo nas relaçóes entre segmentos evangélicos e políticas culturais promovidas pelo Estado (Mafra, 2011; Sant'Ana, 2013).

A proposta deste artigo se concentra em focalizar limites que permeiam definiçôes em torno da categoria "cultura" no universo evangélico, suscitando discussōes sobre as margens que seus sentidos assumem nas combinaçóes entre evangélicos e o "mundo" secular. Antes de mais nada, tenho ciência das implicaçôes problemáticas que o uso do vocábulo "cultura" pode trazer à análise antropológica em termos político-epistemológicos. Estou de acordo com o amplo movimento de crítica, constatado em Abu-Lughod (2018), a uma utilizaçáo insuspeita do conceito. Não obstante, não procurarei acioná-lo de forma a reificar uma "cultura" representativa de um grupo, mas o utilizarei como um conceito a um só tempo nativo e operativo, abundante tanto no campo etnográfico quanto nas referências acadêmicas que trabalham operativamente com o termo. Procuro estar atento às ocorrências e aos usos da categoria no contexto contemporâneo, tomando um caso específico no que tange à realidade evangélica. Considero produtiva uma análise que esteja atenta aos usos da categoria "cultura", desde que a ela se atribuam as devidas aspas, que indicam o que é dito por outrem acerca do termo (Cunha, 2009). 
A partir de uma pesquisa etnográfica realizada junto à Brasa Church, culto e ministério de jovens evangélicos de Porto Alegre/RS ${ }^{4}$, procurarei demonstrar que tensôes e limites em torno da "cultura", tangenciando o gospel, coexistem com novas formas de adoração e engajamento com o "mundo", ou o "secular", no contexto prático das realizaçóes que envolvem a emergência de uma "cultura do Reino" na Brasa Church. Neste ponto, proponho um diálogo com as implicaçôes da disseminação, no seio daquela comunidade religiosa, de uma plataforma discursiva atrelada à chamada Teologia do Domínio, ou Teologia do Reino. Coexistente às elaboraçóes teológicas, a adesão à tendência musical denominada worship afirma sentidos sobre o engajamento da igreja no "mundo" e na "cultura", apresentando limites quanto às definiçôes do "gospel”. Uma compreensão mais acurada sobre as relaçóes com a música e o gospel a partir da Brasa Church depende, então, do entendimento dos deslocamentos que giram em torno das definiçôes e usos locais da "cultura".

Os debates sobre "cultura" e seus tensionamentos no meio evangélico não estão ausentes da literatura especializada sobre o gospel. Ao tratar da popularização da música gospel no Brasil, Magali do Nascimento Cunha (2007) atenta para o que chamou de fenômeno da "explosão gospel”, conferindo atenção à existência de uma certa "cultura gospel" que contornaria a música evangélica no país. De acordo com a pesquisadora, o gospel seria acompanhado por uma confluência de características que marcariam a

4 Utilizei-me de observações participantes e entrevistas, realizadas especialmente com músicos, lideranças e frequentadores/as da Brasa Church, no período entre maio de 2016 e novembro de 2018 . No escopo deste texto, destaco a contribuição de um guitarrista que, em alguns dos trechos de nossas conversas, discorre sobre as relaçóes entre a tendência worship que o grupo/ministério de jovens tem adotado e o gospel, num sentido mais amplo. No contexto de suas afirmaçóes, surgem tensões sobre a categoria "cultura", tomada como um terreno situado no domínio do "mundo" secular. Os dados e argumentos aqui apresentados fazem parte de uma pesquisa que resultou na elaboração de minha dissertação de mestrado em Antropologia Social (Aguiar, 2020), defendida junto ao PPGAS/UFRGS. 
identidade social e religiosa dos evangélicos no Brasil contemporâneo. Visto dessa perspectiva, ele não consistiria simplesmente em um gênero musical ou um sinônimo de música evangélica; mais que isso, tratar-se-ia do eixo central de uma "cultura evangélica". Sustentada pela forte propagação midiática que experimentou, a "cultura gospel” teria nascido a partir da modernização estética alcançada pelo gênero musical nos anos 1980, quando da introdução e adaptação à mensagem religiosa de ritmos seculares outrora considerados "mundanos".

É sugestiva a atribuição evangélica do "mundo" e da "cultura" como lugares eminentemente vinculados ao secular. Bandeira (2014) aponta, de forma bastante contundente, para a centralidade das disputas em torno das definiçóes do sagrado e do secular no mundo gospel. De acordo com a autora, a música gospel não deve ser tomada a priori como sacra ou profana, mas vista em termos do processo constante de negociaçáo de sentidos que a envolve, promovido pelos agentes e instituiçóes empenhados em sua (re) produção. Como veremos mais adiante, as fronteiras entre sagrado e secular, refletindo a dualidade igreja/mundo tradicional ao universo evangélico, têm operado como mecanismos de tensão não somente no caso brasileiro, mas também no estadunidense, quando relacionado, por exemplo, à Contemporary Christian Music (CCM).

Este trabalho não toma por objetivo propor definições acerca do que seja uma "cultura evangélica" ou uma "cultura gospel" no Brasil. Fazê-lo desta maneira seria incorrer nas artimanhas da reificação do conceito de "cultura" como um instrumento de representação típico-ideal de um público evangélico homogêneo. Longe disso, em um movimento distinto e com propósitos diferentes, trata-se de considerar a existência de limites que se colocam a definiçóes genéricas do gospel, desde diferentes sentidos que orbitam em torno do conceito de "cultura" e das relaçóes evangélicas que, ao passar por esta categoria, são efetivadas em conexão com o domínio do "mundo", ou o espaço do "secular". Nas páginas seguintes, procuro descrever uma visáo de música e igreja que rapidamente ganha eco e popularidade entre jovens evangélicos - o worship. Procuraremos tratar o worship, tendência que marca 
as práticas dos jovens da Brasa Church, em Porto Alegre/RS, como uma forma de aprofundar as dimensóes do gospel, não contrapondo ou reduzindo, portanto, um termo ao outro, mas considerando a heterogeneidade que se esconde sob as designaçôes genéricas do gospel. Desta forma, intentaremos explorar as implicaçôes do ideal de "cultura do Reino" para as concepçôes correntes de "cultura".

\section{WORSHIP: A ADORAÇÃO NA BRASA CHURCH}

As noites de sábado são agitadas por um clima de festa na Avenida Dr. Carlos Barbosa, no bairro da Azenha, em Porto Alegre. Perto do antigo Estádio Olímpico, uma multidão de jovens se reúne semanalmente para cantar, orar e conviver em um ambiente repleto de luzes coloridas e músicas altissonantes. A fachada discreta da Igreja Brasa contrasta com a animação da juventude, que se encontra em meio a rodas de conversa um pouco antes do início dos cultos. Os horários são dois: às $18 \mathrm{~h}$ e às $20 \mathrm{~h}$. O serviço religioso, em ambos as reunióes, costuma durar cerca de duas horas. No interior da igreja, o cenário dificilmente evoca a um visitante desacostumado a imagem de um recinto religioso, exceto, talvez, pela presença dos bancos de madeira rústicos, comuns às igrejas protestantes mais antigas. O lugar predominantemente escuro - a frente do púlpito fica coberta por uma cortina preta -, as luzes de led e o som alto, aliados a um forte apelo visual representado por telóes centralizados junto ao púlpito, são elementos que trazem à tona aspectos da identidade da Brasa Church - culto e movimento de jovens da Igreja Brasa - e ajudam a traduzir a visão de igreja adotada e defendida pelos jovens daquela comunidade evangélica desde o final de 2013.

De origem batista, a Brasa é uma das igrejas evangélicas mais antigas de Porto Alegre. Fundada em 1910 sob o nome de Primeira Igreja Batista Brasileira de Porto Alegre, a instituição manteve-se como uma igreja batista tradicional por mais de sete décadas. Em 1986, uma experiência em um dos cultos regulares da igreja acarretou um processo de renovação, alterando 
os rumos de sua história. Durante um momento de louvor, conta-se que um grupo de jovens foi batizado com o Espírito Santo, começando a falar e cantar em línguas espirituais. Trata-se do batismo pelo Espírito Santo como interpretado pelos pentecostais, que acreditam ser a glossolalia - a habilidade ou dom de falar em línguas espirituais, incompreensíveis à inteligência humana - a manifestação visível do recebimento do batismo no Espírito. Na ocasião do fenômeno, um membro da igreja tirava fotografias do culto. As imagens, ao serem reveladas, mostraram algo como chamas ou brasas de fogo cobrindo as pessoas que haviam sido batizadas. A partir desse acontecimento, a igreja se dissociou da Convenção Batista Brasileira (CBB) e se tornou uma denominação evangélica independente, adotando o nome de Ministério Brasa. Com o crescimento dos anos seguintes e a nova orientação teológico-doutrinária, a Brasa se expandiu pelo sul do Brasil e posteriormente se transnacionalizou para a Europa. Assim como outras igrejas porto-alegrenses, a Brasa está inserida em uma política de transnacionalização e de "reconquista espiritual da Europa" (Oro; Alves, 2015; Oro, 2017).

A Igreja Brasa matriz conta com diferentes cultos ao longo da semana. Os mais tradicionais ocorrem aos domingos e costumam agregar um público de faixa etária mais avançada, assim como os cultos durante a semana. As reuniốes que mais se diferem das demais são as da Brasa Young, nas sextas à noite, reunindo os adolescentes da igreja, e a Brasa Church, o culto jovem noturno de sábado. No site da Brasa Church há uma descrição própria do culto: "A Brasa Church é o encontro de jovens (entre 8 e 80 anos!) da igreja matriz do Ministério Brasa [...]"5. Não há uma faixa etária definida para os cultos da Brasa Church, mas neles é predominante a presença de jovens. Cenários parecidos podem ser encontrados também em outras igrejas de Porto Alegre e região metropolitana. Cultos e movimentos vinculados à juventude das igrejas, assim como o da Brasa Church, mas dotados de suas especificidades e diferenças, têm sido realizados, por exemplo, pela Igreja

${ }^{5}$ Disponível em: http//:www.brasachurch.com/. Acesso em: 29 nov. 2018. 
Batista Mont'Serrat, de Porto Alegre, e pela Assembleia de Deus de Gravataí (RS). Tais reunióes são realizadas geralmente nas noites de sábado, à parte dos cultos mais tradicionais das igrejas.

No interior da Brasa Church, tudo parece depender do ritmo das músicas. No púlpito rotineiro, modificado pelos aspectos estéticos que caracterizam o culto no estilo worship, está montado o palco no qual os músicos, com seus instrumentos, são os condutores do momento de adoração. As músicas contam com letras repetitivas, ao estilo de marchas-baladas lentas com grande vocalização. Há uma grande modulação entre tons menores e maiores ${ }^{6}$. Em um estilo marcado pela predominância de certas variaçóes do pop rock, a musicalidade é propícia a que todos participem da vocalização, não se restringindo esta tarefa aos músicos que tocam e cantam em suas funçôes ministeriais. As cançóes reproduzidas pela banda da Brasa Church e entoadas durante os cultos vêm de repertórios internacionais. A Brasa Church recebe influência de bandas de fama e circulação global, que compartilham da mesma tendência worship. É o caso, por exemplo, da australiana Hillsong United ${ }^{7}$ e das norte-americanas Jesus Culture e Bethel Music. Desta última é a canção "Reckless Love", cuja versão em português,

6 Essa definição mais técnica é dada por Ricardo Feltrin, que assina o artigo no blog UOL Música intitulado "Entenda o Hillsong, um dos maiores fenômenos do gospel mundial". UOL Música, 03/02/2015. Embora a referência direta seja a musicalidade da Hillsong Church, o autor fala da tendência worship de um modo geral. Disponível em: http:// uolmusica.blogosfera.uol.com.br/2015/02/03/entenda-o-hillsong-um-dos-maiores-fenomenos-do-gospel-mundial. Acesso em: 19 out. 2018.

7 Um estudo sobre as relaçôes da Hillsong Church com o Brasil pode ser encontrado em Rocha (2016). Acrescento uma importante informação, constatada em campo: de acordo com Lucas, um dos líderes da Brasa Church, a igreja tem mantido um intercâmbio com a Hillsong, através da instituição educacional Hillsong College. Nos últimos anos, ao menos oito jovens da Brasa teriam estudado/estariam estudando no país, como fruto de uma parceria com a Hillsong Leadership Network, uma rede de formaçáo de líderes supradenominacional (ver o site oficial da rede: http://www.hillsong.com/network/).

Debates do NER, Porto Alegre, ano 20, N. 37, P. I4I-I67, JAN./Jul. 2020 
"Ousado Amor", ganhou um clipe da Brasa Church no YouTube ${ }^{8}$ Na letra, um relacionamento bastante próximo e íntimo entre o fiel e Deus é enfatizado: "Antes de eu falar/ Tu cantavas sobre mim/ Tu tens sido tão, tão bom pra mim/ Antes de eu respirar/ Sopraste tua vida em mim/ Tu tens sido tão, tão bom pra mim.”

Figura 1 - Interior da Igreja Brasa matriz, durante um culto da Brasa Church

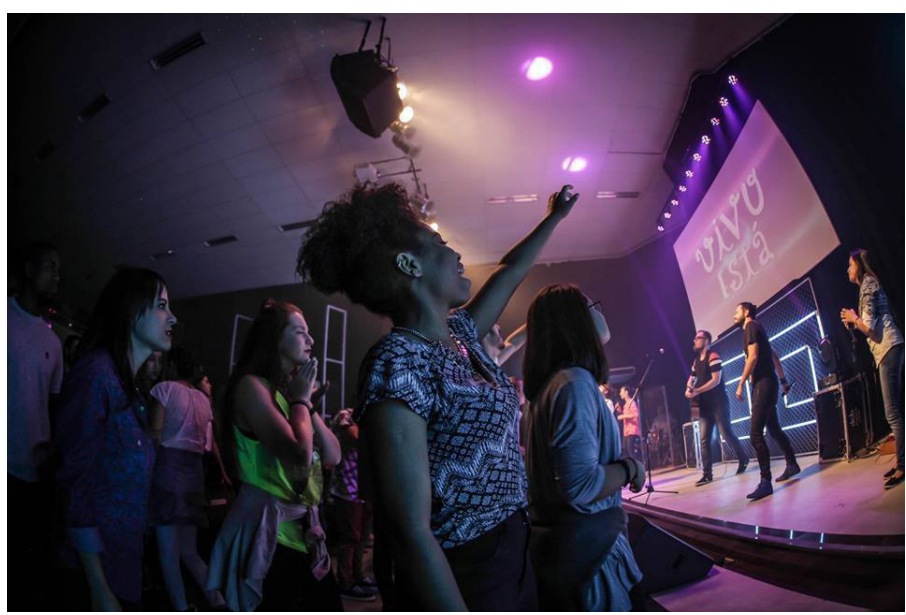

Fonte: Reprodução do Facebook da Brasa Church. ${ }^{9}$

O próprio termo worship, traduzido do inglês, quer dizer "adoração", num sentido menos ritualístico e mais de envolvimento pessoal com a religiāo. A tradição em que o worship se inscreve tem sua origem no interior do panorama da música evangélica estadunidense do último quarto do século XX. Em sua tese de doutorado, Nina Rosas (2015a) observa que, no contexto daquele país, a categoria gospel está mais atrelada à música cristã black do que a um gênero musical que abrange vários estilos evangélicos. Rosas teceu um breve apanhado das transformaçóes musicais no contexto

8 Disponível em: http://www.youtube.com/watch?v=1 mTilq1dFSw. Acesso em: 29 nov. 2018.

9 Disponível em: http://www.betaredacao.com.br/cristaos-diferentoes-um-jeito-novo-de-ser-igreja/. Acesso em: 29 nov. 2018.

Debates do NER, Porto Alegre, ANo 20, N. 37, P. I 4I-I67, JAN./JUl. 2020 
posterior ao Jesus Movement, movimento avivalista evangélico ocorrido no final dos anos 1960 e início da década de 1970 nos Estados Unidos, e que consistia em uma espécie de contracultura conservadora com grande ênfase sobre a música (Nekola, 2013). As igrejas que surgiram do Jesus Movement foram chamadas de new paradigm churches, diferenciando-se das igrejas do mainstream local, entre outros aspectos, pela criação de um novo estilo de adoração congregacional (Miller, 1997). Nessa nova configuração, ritmos populares ganharam proeminência e a música foi alçada a um patamar mais elevado dentro da ritualística dos cultos.

No final dos anos 1970, dois grupos gerados no seio da musicalidade cristã estadunidense se constituíram a partir de distintas relaçôes com o mercado fonográfico. Ingalls (2008) observa que a Contemporary Christian Music (CCM) foi organizada a partir de uma proposta orientada para o consumo de um público interno e externo, através de uma produçáo musical centralizada em Nashville, Tennessee, coração da indústria fonográfica nacional. Enquanto isso, gravadoras religiosas como a Maranatha!, a Integrity e a Vineyard focaram suas produçóes em música exclusivamente congregacional, de circulaçáo interna ao público das igrejas. Esse repertório, comumente tocado em encontros e reuniôes interdenominacionais de juventude, promovidos por organizaçóes paraeclesiásticas, especialmente do sul da Califórnia, passou a ficar conhecido como Modern Worship Music (MWM). Em sua gênese e em seus desdobramentos, a categoria se confunde com o worship que se populariza no Brasil anos depois. Com um grande crescimento nas décadas de 1990 e 2000, a produção musical do worship toma nova forma e extrapola os limites congregacionais das igrejas estadunidenses, aproximando-se do mercado da música secular e passando a receber influências de outros lugares do mundo, como do Reino Unido, na "invasão britânica”, e da Austrália, no caso da Hillsong Church e seu ministério musical (Kelman, 2018).

As fronteiras entre a CCM e a MWM tornam-se, então, mais porosas e menos distantes. Howard e Streck (1999) buscam analisar as relaçóes entre música cristã e mercado secular no contexto dos Estados Unidos a partir de 
três grupos que expressam diferentes leituras e modos de atuação com relação à "cultura”, encarada pelos evangélicos como um espaço aprioristicamente secular: a) para os separatistas, haveria uma distância intransponível entre música religiosa e cultura secular, porque, segundo eles, as dualidades igreja/ mundo, bem/mal, certo/errado permaneceriam fundamentais e intrínsecas à vida cristã; b) para os integralistas, as distinçôes entre sagrado e secular deveriam ser relativizadas, na medida em que a cultura estaria em uma condição de imperfeição, mas que poderia ser melhorada em harmonia com Cristo e seus princípios (Cristo seria o que de melhor haveria na cultura); c) enquanto que, para os transformadores, sendo a cultura um meio corrompido, mas não intrinsecamente mau, fazia-se necessário transformá-la por meio de influências cristâs exercidas sobre o "mundo" em seus diversos âmbitos. A música, entendida como um produto estético e artístico, não estaria fora desse movimento transformativo da cultura.

Apesar de consistirem em generalizaçóes muito limitadas, estas três categorizaçóes nos permitem refletir sobre distintas relações evangélicas com o conceito de "cultura", não somente no caso estadunidense, mas também no brasileiro. Em minha avaliação, nenhum dos grupos descritos por Howard e Streck (1999) teria rompido definitivamente com a dualidade igreja/mundo, ou sagrado/secular. Eles apenas a encaminharam em um ou outro sentido: ao separar-se da cultura, integrar-se a ela ou transformá-la, de qualquer modo, mantém-se deslocada a igreja do "mundo". Nina Rosas (2015a) percebe a conexão que há entre uma destas categorias, a de transformadores, com as relaçôes que se desenvolvem nos marcos da atuação musical da banda Diante do Trono, considerada uma das maiores referências da música gospel brasileira. Ligada à Igreja Batista da Lagoinha, em Belo Horizonte, a banda liderada por Ana Paula Valadão compartilha de uma série de características que a aproximam de um discurso de "transformação da cultura" pela atuação cristã na sociedade. Mais adiante, voltaremos a explorar este ponto, relacionando-o ao ideal de "cultura do Reino" e à Teologia do Domínio. Por ora, voltaremos à Brasa Church, locus etnográfico que pode nos revelar tensóes envolvendo as relaçóes entre música gospel e cultura no Brasil. 


\section{TENSÓES DA “CULTURA” A PARTIR DO WORSHIP NA BRASA CHURCH}

No escopo da pesquisa que compreende os resultados abordados por este artigo, e dentro do conjunto de entrevistas que realizei com músicos, lideranças e membros da Brasa Church, as interlocuçôes com o guitarrista Caio receberam destaque na construçáo dos argumentos do texto. Isto se deu, inicialmente, pela pertinência de dois motivos principais: pelo amplo conhecimento do músico sobre a popularização da tendência worship no meio evangélico, a partir de sua experiência e trânsito por diferentes denominaçôes (acompanhei o processo de vinculaçáo institucional de Caio à Igreja Brasa, vindo da Assembleia de Deus); e por se tratar de um músico cujas conexôes imediatas com a Brasa Church já existiam antes de sua adesão institucional (ainda assembleiano, Caio já frequentava a Brasa Church, e seu irmáo já ocupava a posiçáo de tecladista na banda).

Durante nossas conversas, frequentemente ouvi que o worship vai além de um movimento ou tendência musical. $O$ guitarrista afirma que a categoria faz referência "ao tocar, ao falar, ao discipular, ao ajudar, ao agir", ou seja, a diferentes ênfases da vida cristâ. Dito de outro modo - e ainda parafraseando o músico -, "o worship é um estilo de vida". Ao passo que é visto mais nitidamente como o sustentáculo de uma forma ou tendência musical específica, ele consiste em um modo de viver o cristianismo que se espraia para outras possibilidades de atuaçấo cristã na igreja e no "mundo". Assim, para o guitarrista, é tanto verdade que o worship é música quanto ele é "discipulado, pregação, beneficência, entre outras coisas". O caráter abrangente do worship pode ser evidenciado pelas letras de suas cançóes, que buscam enfatizar diversas entradas e possibilidades para a vida cristã. As cançôes náo se reduzem a uma temática predominante, apesar de possuírem marcas comuns, como o apelo à relaçáo pessoal fiel-Deus e a repetiçáa constante de versos-chave. Podemos lembrar, com a leitura de Mendonça (2014), que isso não acontece da mesma forma com a música gospel e sua 
vertente mais popular, aquela relacionada às narrativas de vitórias pessoais, milagres e curas.

Segundo o músico, existe uma distância entre o worship e o gospel hegemônico ${ }^{10}$, na medida em que aquele "te dá uma liberdade maior para adorar a Deus". Essa liberdade pode ser levada em conta em termos de uma expressão de aspectos corporais que não são vislumbrados da mesma maneira em certas apresentaçóes gospel, seja em igrejas ou em espaços fora delas, como em shows públicos. A este respeito poderíamos estar falando de um comprometimento do worship com a expressão da emotividade e sensibilidade dos fiéis através de uma musicalidade mais "interiorizante", de contrição pessoal; ou poderíamos entendê-lo - e neste ponto a senda de discussão se amplia e se torna ainda mais produtiva - como uma possibilidade de fuga a uma forma de produção musical hegemônica ao campo evangélico, fortemente ligada ao mercado e à midiatização. É esse, no seu entendimento, o caso do gospel, tomado como um movimento que, de certa maneira, tem "banalizado" o uso e a difusão da música evangélica "pela busca da fama e do dinheiro". A construção de carreiras gospel é vista com desconfiança pelo músico, pois não significa necessariamente que a bênção de Deus esteja sobre um cantor/cantora. Segundo ele, "para ser gospel, é preciso apenas falar de Deus”. Ou seja: a mensagem da música evangélica corre o risco de se tornar simplesmente um produto nas mãos da indústria cultural, quando acionada no mercado de forma a enfatizar a fama e a construção de carreiras artísticas em detrimento de um serviço religioso voluntário. Em outras palavras ditas pelo músico: "Eu vejo o gospel sem uma visão, mas como [a expressão de] uma pessoa que descreve [sic] que é de Deus".

É preciso enfatizar que esse entendimento sobre o gospel não necessariamente encontra na abertura ao mercado e às mídias um problema para a música cristã. Para Caio, pode haver uma influência do gospel sobre o

\footnotetext{
${ }^{10}$ Tomo "gospel hegemônico" em referência às citaçôes do músico entrevistado. Para ele, o termo "gospel” está atrelado à produção musical do mainstream do gênero, representado por grandes gravadoras e artistas do mercado.
}

Debates do NER, Porto Alegre, Ano 20, N. 37, P. I 4 I-I67, JAn./JUl. 2020 
mundo secular, e vice-versa. A influência pode ser tanto evangelizadora quanto "banalizadora", pois, na adesão a uma plataforma mercadológica e artística, a construção de uma carreira de fama pelo artista gospel pode promover uma perda do sentido mais religioso que a música evangélica possui. Essas são ocasiôes em que "exalta-se mais o homem do que a Deus", fazendo com que a música seja instrumentalizada pela indústria cultural. $\mathrm{O}$ mercado de artigos que recebem o rótulo gospel pela sua identificação com mensagens bíblicas e valores morais cristãos também pode ser atingido pelo mesmo processo de "banalização", especialmente quando as mercadorias se referem a marcas de artistas gospel e de pregadores famosos. Não obstante as observaçóes que questionam os limites da autenticidade da inserção do gospel na sociedade, no tocante à estruturação de um mercado gospel em torno da música, Caio não tem dificuldades em admitir que "o gospel é uma grande cultura que está fazendo parte desse século”. Prova disso seria, a seu ver, a grande circulação do gênero entre consumidores de diferentes preferências religiosas.

Pensar controvérsias em torno do termo "cultura" pode ser um modo profícuo de se chegar a diferentes concepçóes sobre a categoria. De minhas conversaçóes com Caio surgiram indefinições e tensôes em torno do conceito. Se, para ele, por um lado, o gospel era uma "cultura", uma vez que estava em contato intenso com o "mundo" exterior à igreja - e aqui a cultura está externalizada e deslocada para o secular -, essa inserção teria seus limites, na medida em que o gospel estaria sendo "banalizado" por uma linguagem midiática e mercadológica que afetaria o sagrado. O que, então, estaria em jogo? Ao falar sobre o gospel, Caio mencionou: "Eu não acho o gospel importante, nem para a igreja e nem para os fiéis". Sobretudo, o caso de Caio é interessante e suas colocaçóes merecem maior destaque dentre os dados colhidos em campo porque ele mesmo participou ativamente de um dos maiores eventos públicos de música gospel do país, o Festival Promessas, realizado anualmente junto à Festa Nacional da Música. Na edição de 2017, que teve Porto Alegre como sede e que pude acompanhar presencialmente, o músico esteve no palco, tocando sua guitarra e acompanhando as cançóes 
dos cantores Maurício Paes e Regis Danese. Essa participação se tornou possível através da organização do evento por uma rede local de músicos, centralizada na figura do cantor Fabinho Vargas. A edição de 2017 do Festival Promessas recebeu cobertura e foi transmitida ao vivo pelo portal de internet da maior rede de comunicação do Brasil.

A participação do músico Caio no Festival Promessas, assim como o contrato recentemente assinado entre a banda da Brasa Church, agora denominada Brasa Church Music, com a gravadora Onimusic - conferir a nota número 9 e os comentários a este respeito na última seção do texto são elementos que fornecem margem à relativização do teor distintivo que contorna as afirmaçóes do músico sobre as relaçôes entre o worship e o gospel hegemônico. Mais uma vez, cabe destacar que ambos os movimentos não devem ser vistos em contraposição, à maneira como se o worship revelasse uma negaçáo ou um rompimento com o gospel. Ao invés disso, o que a tendência parece estabelecer é uma condição limitadora a definiçóes mais amplas do gospel enquanto a base de uma "cultura" ancorada nas mídias, no mercado e na indústria cultural. Há a ocorrência de tensóes e dissonâncias quanto à participação evangélica nestes âmbitos. As tensôes em torno dos lugares que o conceito de "cultura" assume no discurso do músico também apontam para relaçôes evangélicas com o "mundo": a potencial "banalização" do sagrado está calcada na possibilidade de separação entre o que é concernente ao âmbito da adoração genuína e os perigos "da fama e do dinheiro", que fazem "exaltar mais o homem do que a Deus". Em que pese esta localização externa apriorística do "mundo", há modulaçôes entre diferentes definiçôes de "cultura" no meio evangélico, tornadas práticas à medida que ela vai sendo deslocada, por exemplo, de uma posição separatista para uma posição transformacionista, conforme procurei sugerir anteriormente. 


\section{"A ÂNCORA E O VENTO": \\ UMA VISÁO DE IGREJA, MÚSICA E CULTO}

Ainda a discorrer sobre o worship, o guitarrista menciona que a tendência pode ser tomada enquanto uma visão, no sentido de ideal ou perspectiva adotada pela Brasa Church. E que esta visão (grafada ao longo deste texto em itálico, para distingui-la da "visão" profética, da "visão" sensorial e de outros sentidos que não os aqui pretendidos) possui ao menos duas dimensóes constituintes: a visão de Reino e a visão de culto. A "visão de Reino", segundo ele, referir-se-ia aos valores, princípios, doutrinas e ensinamentos religiosos e estaria, portanto, revestida de um certo caráter de imutabilidade. Ao passo que a "visão de culto" designaria os elementos que performam o culto da igreja, como o estilo musical, o vestuário utilizado pelos fiéis e líderes, os aspectos corporais das pessoas, o templo, o uso de tecnologias como os telóes, os costumes e tradiçóes, etc. Tudo, enfim, que dissesse respeito ao mutável, de acordo com o tempo histórico e a cultura local, faria parte da "visão de culto". Se o worship é uma visão integral de igreja, um "estilo de vida", ela passa, portanto, pelos dois âmbitos. Pela "visão de Reino", porque tem uma mensagem a conservar; e pela "visão de culto", porque embasa a performance e os demais elementos concernentes ao culto.

Num primeiro momento, o worship parece se revestir de um caráter revolucionário, no sentido menos político do termo. No entanto, pensá-lo enquanto algo essencialmente novo pode ser o cometimento de um equívoco. A metáfora bíblica do "vinho novo em odres velhos", acionada por Cunha (2007) em sua análise da "cultura gospel” no Brasil, é sugestiva a esse respeito. O questionamento está posto sobre a amplitude de uma "modernização" do gospel que preserva elementos de conservação em seu interior. A mudança ritualística nas igrejas e a transformação musical na produção do gospel não foram acompanhadas por uma atualização substancial do discurso religioso, cujas bases tradicionais, incluindo-se nelas a dualidade igreja/mundo, são mantidas. Quanto ao worship, vislumbramos um movimento que parece modificar o cenário jovem de igrejas de diferentes espectros ideológicos 
no campo evangélico, expandindo-se de igrejas pentecostais a históricas. Todavia, apesar da ruptura com elementos que compóem os domínios mais tradicionais da "visão de culto", o worship apresenta uma conservação da "visão de Reino" que é comum à maioria das igrejas evangélicas brasileiras.

As pregaçóes nos cultos da Brasa Church ajudam a ilustrar este ponto. Com raízes batistas, a Brasa dá lugar especial ao sermão em seus cultos jovens. A atenção dos presentes é grande. $\mathrm{O}$ barulho e a animação do ambiente cessam quando o momento é de ouvir o sermão. Geralmente, o pregador é o pastor de jovens, Mauricio - de quem partiu a idealização da Brasa Church em 2013 -, um dos líderes do grupo ou um convidado externo. Apesar da "animação" e da "liberdade corporal" que o estilo promove - nas palavras de Caio, "o worship te dá uma liberdade" - a música não substitui o lugar da pregação na Brasa Church. Em que pese o lugar importante rendido à musicalidade, a Palavra (sermáo) preenche grande parte da duraçáo do culto, e seu conteúdo reflete, em grande parte, os ensinamentos evangélicos mais tradicionais, como o apelo a uma vida piedosa e à necessidade de que os jovens da igreja façam a diferença no "mundo".

Antes de adentrar ao assunto da "cultura do Reino" e de sua relaçáo com a Teologia do Domínio, é de alguma utilidade falar dos lemas anuais da Brasa Church, para que melhor se compreenda os elementos que constituem sua visão, para além do que se descreve sobre o worship. Todos os anos, a Brasa Church adota uma frase diferente como lema, ajudando a traduzir sua visão mais geral para a comunidade. Em 2016, o lema adotado foi "A âncora e o vento" (figura 2). Uma frase que frequentemente definia o foco do ano era "Firmados na Palavra, livres no Espírito", expressão que aludia à âncora como um objeto de firmeza e representava a ideia de liberdade encontrada no vento. A motivação do lema daquele ano consistia em mostrar que o foco da igreja estava colocado em preservar a Palavra - os ensinamentos da Bíblia Sagrada -, mas sem que se perdesse a liberdade que se possui no Espírito [Santo]. O lema "A âncora e o vento" traduz a ideia presente nos dois domínios que constituem a visão de igreja. Enquanto a âncora é uma referência correspondente à "visão de Reino", o vento faz alusão direta à 
"visão de culto" da Brasa Church. Os lemas dos anos seguintes seguiram em trilhas semelhantes, mas se debruçaram sobre outras direçôes. Em 2017, a frase que definia o foco da Brasa Church era "Contágio de vida" e, em 2018, "Grandiosamente simples".

Figura 2 - Lema da visão 2016 da Brasa Church: "A âncora e o vento"

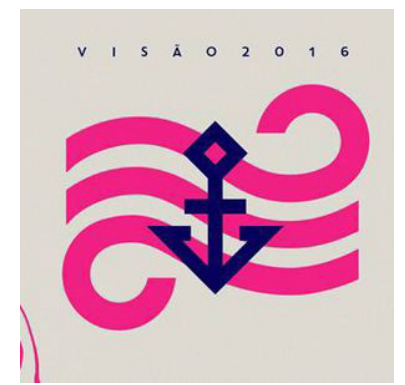

Fonte: Perfil da Brasa Church no Mixcloud. ${ }^{11}$

Os lemas da Brasa Church, especialmente o de 2016, refletem a visão de igreja defendida pelos jovens que nela congregam. Em todos os cultos, seja através da Palavra ou da música, eles são chamados a viver "firmados na Palavra" e "livres no Espírito", sendo estimulados a fazer a diferença no "mundo" - em casa, no trabalho, nas ruas, nas universidades ou em qualquer outro ambiente. Dentro de uma série de mais de vinte cultos que pude acompanhar presencialmente de maio de 2016 a novembro de 2018, notei como constante a presença, nas pregaçôes e comunicaçóes da Brasa Church, de uma retórica que aposta na ideia de "cultura do Reino" como balizadora de um processo de influência e transformação da sociedade e da "cultura” pelos princípios cristãos.

11 Disponível em: http://www.mixcloud.com/brasachurch/a-\%C3\%A2ncora-e-o-vento-mauricio-martins/. Acesso em: 29 nov. 2018.

Debates do NER, Porto Alegre, ANo 20, N. 37, P. I4I-I67, JAN./JUl. 2020 


\section{A “CULTURA DO REINO” NO CONTEXTO DA TEOLOGIA DO DOMÍNIO}

A "cultura do Reino"12 está inserida em uma interpretação teológica que busca reunir os esforços de evangelização cristã com o ideal de que o Reino de Deus deve ser estabelecido "no coração e na mente das pessoas", onde quer que elas estejam - e isso pressupóe a presença cristã no "mundo", ou na esfera secular, como transformativa. Rosas (2015b) procurou perceber como um discurso semelhante é acionado pela banda Diante do Trono, quando, no contexto de seu ministério musical, é transmitida a necessidade de que os cristãos influenciem e participem mais ativamente de diferentes esferas da vida social, o que inclui, por exemplo, a política, as artes e as mídias. Não passa por alto o percurso investigativo realizado pela autora em sua pesquisa, observando como as açốes da Diante do Trono estão vinculadas às práticas que circulam por uma rede de relaçôes que têm seu ponto de irradiação situado fora do Brasil, ou mais especificamente, em um grupo de lideranças influenciadas pela chamada Teologia do Domínio, ou Teologia do Reino.

No final dos anos 1980, a partir do Fuller Theological Seminary, na Califórnia, o mais famoso centro de formação pentecostal estadunidense, começaram a tomar forma as ideias do teólogo Peter Wagner, que acreditava ser necessário resgatar o protagonismo cristão no seio dos diversos âmbitos da vida social. Segundo ele, dentro da chave da narrativa bíblica, Deus teria criado o ser humano e lhe concedido o domínio sobre a natureza e tudo o que a compóe, característica esta que teria se perdido após a entrada do pecado no mundo. Depois do sacrifício vicário de Jesus Cristo, este domínio

${ }^{12}$ Em buscas na Internet, encontrei ao menos dois ministérios paraeclesiásticos diferentes adotando o nome de "Cultura do Reino". Um é oriundo de São Paulo, e o outro é de Jaraguá/SC. Respectivos sites: http://www.culturadoreino.org/ e http://www.culturadoreino.com/. Outro ministério paraeclesiático importante, e que age no mesmo sentido, é o Dunamis Movement, liderado por Teo Hayashi, que mantém relação direta com a Brasa Church e cujo foco primordial é o nicho universitário. Site: http://www.dunamismovement.com/. Acesso a todos os sites em: 29 nov. 2018.

Debates do NER, Porto Alegre, Ano 20, N. 37, P. I 4I-I67, JAn./JUl. 2020 
deveria ser recuperado, pois, com a derrota de Satanás, o controle do mundo teria passado definitivamente para o Reino de Deus. Como cidadáos deste Reino, os cristâos deveriam reivindicar a liderança e o domínio da Terra pela expansão dos princípios que sáo inerentes ao Reino de Deus (Wagner, 2008). Evidentemente, as relaçóes com o "mundo" e a cultura mudam nas implicaçôes advindas de tal atitude. O que antes era visto como demoníaco e intrinsecamente mau agora passa a ser um campo de disputas pela promoçáo do Reino de Deus.

A "cultura do Reino" pressupóe um processo que começa interiormente, com a conversão pessoal, e alcança a coletividade, através da agregação dos sujeitos religiosos ao povo que constitui o Reino apregoado. No dia 24 de novembro de 2018, o pregador do culto da Brasa Church foi Teo Hayashi, líder de um movimento paraclesiástico chamado Dunamis Movement, voltado, sobretudo, ao trabalho evangelístico com jovens universitários. No site do Dunamis, fica evidente a ideia de que a cultura deve ser transformada pelos princípios do Reino de Deus: "Nós buscamos DESPERTAR uma geraçáo para que ela venha ESTABELECER a Cultura do Reino de Deus na Terra e assim TRANSFORMAR a sociedade a sua volta". ${ }^{13}$ Durante sua explanação, Teo Hayashi disse que estava espantado com "o grande avivamento" pelo qual a nação estava passando nos últimos tempos, em referência ao crescimento evangélico. Ele sugeriu que "o povo evangélico já não é mais minoria" e enfatizou o protagonismo dos jovens nesse processo de "avivamento" que, a seu ver, "tem transformado a nação".

Elementos tais como "nação", "povo" e "Reino" são frequentemente fundidos à imagem do Brasil, que é visto como uma terra a ser conquistada para o Reino de Deus. Tal movimento tem encaixe no ideário teológico formulado por Peter Wagner. Não se trata mais de rejeitar o "mundo" e de situar a "cultura" no secular, deixando-a por lá, enquanto algo à parte ou perigoso para a igreja. No contexto da rede que comporta ministérios jovens

${ }^{13}$ Disponível em: https:/www.dunamismovement.com/quem-somos/. Acesso em: 29 nov. 2018.

Debates do NER, Porto Alegre, Ano 20, N. 37, P. I4I-I67, JAn./Jul. 2020 
que compartilham da tendência musical worship, sejam eles denominacionais ou paraeclesiásticos, a atitude evangélica que se baseia na "cultura do Reino" tem se aproximado de uma busca pela transformação e conquista da cultura, para que esta reflita o pleno domínio que o Reino deve possuir. No cenário musical, as decorrências de tal disposição teológico-prática ainda não foram amplamente estudadas, e o trabalho de Rosas (2015b) acima mencionado é um pioneiro nesse sentido. A Igreja Batista da Lagoinha, à qual é ligada a Diante do Trono, tem adotado uma tendência worship que em muito se assemelha à da Brasa Church, aproximando-se, inclusive, de referenciais da Hillsong Church e de outras igrejas de orientação próxima. Recentemente, a líder de louvor da Igreja Batista da Lagoinha, Arieta Magrini, lançou nas plataformas digitais uma canção gravada em parceria com a banda da Brasa Church, intitulada "Não mais escravos". E, sob o selo da mesma gravadora à qual Arieta Magrini é vinculada - a Onimusic - grava o Dunamis Music, braço musical do Dunamis Movement ${ }^{14}$.

\section{CONSIDERAÇÕES FINAIS}

Após levar a cabo uma pesquisa sobre o worship desde o contexto da Brasa Church, resulta-me categórico haver uma relação significativa, profícua a novos investimentos de pesquisa, entre "cultura do Reino" e concepçôes evangélicas, sempre múltiplas e complexas, acerca do termo "cultura". Para acessar pontos dentro dessa discussão, inclusos no debate sobre religiáo e espaço público, a música, em suas práticas por ministérios jovens ligados ao worship, pode ser uma chave para além das iniciativas em espaços político-institucionais que se ocupam em utilizar o conceito de "cultura" como uma justificativa na busca de políticas culturais (uma vez mais, retorno aos

${ }^{14}$ Este ponto merece ser devidamente sublinhado: em março de 2019, a banda da Brasa Church também passou a fazer parte do cast da Onimusic. As consequências desta adesão, não sendo cruciais para os propósitos deste artigo, são comentadas detalhadamente no capítulo 3 de minha dissertação de mestrado (Aguiar, 2020). 
trabalhos de Mafra, 2011, e Sant'Ana, 2013). Ao considerar a pertinência de variados caminhos heurísticos para investimentos de pesquisa futuros sobre o gospel, gostaria de enfatizar pelo menos dois possíveis: um estaria relacionado com a noção de "sensibilidade secular" (Dullo; Quintanilha, 2015), que envolveria evangélicos e espaço público pela via da política e que, conforme entendo, poderia também ser ampliada às relações evangélicas com a "cultura" por meio da música gospel; e o outro, inspirado no trabalho de Almeida (2018) noutro contexto religioso, colocaria ênfase nas combinaçôes do worship com o mercado fonográfico, visando analisar a "cultura" e o "secular" desde as relaçóes entre a música no ritual e a música gravada.

Um caminho que ainda se coloca por percorrer é aquele que busca relacionar as formas de vivenciar a música no contexto evangélico - refiro-me especialmente ao worship, mas apontando para além dele, inclusive para o gospel -, seja em igrejas ou em ambientes externos a elas, notadamente no espaço público, com o conceito de "cultura", explorado tanto no acionamento de políticas culturais estatais (Giumbelli, 2014) como na consolidação de uma indústria cultural gospel brasileira. Considero que as transformaçóes recentes quanto ao panorama evangélico requerem a tomada de um passo analítico para além de definiçóes genéricas do gospel. Os ministérios jovens emergem dotados de um papel de centralidade no seio das novas configurações evangélicas, uma vez que deles têm surgido formas de produção musical que colocam limites à homogeneidade das definiçóes de "cultura gospel" que circulam em diferentes âmbitos.

Se agentes religiosos e políticos têm fomentado iniciativas como a proposição da Lei 12.590/12 (veja-se Sant'Ana, 2013), investindo em justificativas que passam primariamente pela inscrição do gospel no contexto mais amplo de uma definiçáo possível de "cultura", de forma a enfatizar a presença de uma "cultura gospel” no Brasil, esse movimento não precisa ser considerado unânime no universo evangélico. $O$ próprio conceito de música gospel não está definido consensualmente e não opera de forma estanque, mas em constante disputa. Nas observaçóes do guitarrista Caio acerca de uma "banalização" que envolveria o mercado e a indústria cultural gospel quando 
cantores e produtores musicais em geral estariam mais preocupados com a construção de carreiras artísticas e com "a fama e o dinheiro" do que com a mensagem religiosa da música, está aparente que o gospel suscita tensóes que envolvem o que, de forma simplificada, poderíamos chamar de domínios do "secular" e do "sagrado". Seguindo os passos de Bandeira (2017b), admitimos que definir o gospel como sendo ora sagrado, ora profano, pode não ser um investimento analítico tão produtivo quanto considerar as disputas que contornam continuamente as definiçôes desses âmbitos, apostando no gospel como um híbrido, situado entre o sagrado e o secular.

Enquanto aproximaçóes com a esfera "secular" pela via da "cultura gospel" suscitam tensôes, a transformação preconizada pela "cultura do Reino" sugere a existência de margens não lineares quanto ao conceito de "cultura". Nos movimentos que se operam entre o sagrado e o secular, visibilizando seus entrecruzamentos, é que reside uma senda profícua de investigaçáo. $\mathrm{Na}$ medida em que passamos a entender o gospel como uma arena envolta por disputas, conseguimos vislumbrar que as relaçóes entre evangélicos e políticas culturais no Brasil, em especial aquelas que passam pelo marcador da música gospel, podem ser tanto mais produtivas em possibilidades quanto plurais forem essas disputas. A heterogeneidade do campo evangélico é capaz de apresentar diferentes concepçóes acerca do conceito de "cultura", como se pode conferir na promoção da "cultura do Reino" pela Brasa Church e por ministérios paraeclesiásticos ligados ao worship, e em âmbitos variados nos quais a Teologia do Domínio se constitui como um fundamento para açóes evangélicas no espaço público. Mas, ainda além dessa constatação, essas elaborações podem conduzir a novas interpretaçôes acerca das mediaçóes entre Estado, políticas culturais e evangélicos no Brasil a partir da música gospel, desde que se observem as disputas em torno de suas definiçôes. 


\section{REFERÊNCIAS}

ABU-LUGHOD, Lila; REGO, Francisco Cleiton Vieira Silva do; DURAZZO, Leandro. A escrita contra a cultura. Equatorial, Natal, v. 5, n. 8, p. 193-226, 2018.

AGUIAR, Taylor Pedroso de. A "cultura" para o Reino: materialidades e sentidos da adoração em uma juventude evangélica em Porto Alegre. 2020. Dissertação (Mestrado em Antropologia Social) - Universidade Federal do Rio Grande do Sul, Porto Alegre, 2020.

ALMEIDA, Leonardo Oliveira de. Fonografia religiosa afro-gaúcha: o ritual e o gravado no contexto de novas artisticidades. Debates do NER, Porto Alegre, v. 1, n. 33, p. 197-234, 2018.

ALMEIDA, Ronaldo de. A expansão pentecostal: circulação e flexibilidade. In: TEIXEIRA, Faustino; MENEZES, Renata (org.). As religiöes no Brasil: continuidades e rupturas. Petrópolis: Vozes, 2006. p. 111-122.

BANDEIRA, Olívia. Música gospel: aproximaçóes e conflitos entre o sagrado e o secular. In: REUNIÂO BRASILEIRA DE ANTROPOLOGIA, 29., 2014, Natal. Anais [...]. Natal: ABA, 2014. Disponível em: http://www.29rba. abant.org.br/resources/anais/1/1401634827_ARQUIVO_ABA_2014.pdf. Acesso em: 29 nov. 2018.

BANDEIRA, Olívia. Música gospel no Brasil: reflexões em torno da bibliografia sobre o tema. Religião \& Sociedade, Rio de Janeiro, v. 37, n. 2, p. 200-228, 2017a.

BANDEIRA, Olívia. O mundo da música gospel entre o sagrado e o secular: disputas e negociaçôes em torno da identidade evangélica. 2017. Tese (Doutorado em Antropologia Cultural) - Universidade Federal do Rio de Janeiro, Rio de Janeiro, 2017b. 
BIRMAN, Patricia. O poder da fé, o milagre do poder: mediadores evangélicos e deslocamento de fronteiras sociais. Horizontes Antropológicos, Porto Alegre, v. 18, n. 37, p. 133-153, 2012.

CUNHA, Magali do Nascimento. A explosão gospel: um olhar das ciências humanas sobre o cenário evangélico no Brasil. Rio de Janeiro: Mauad X: Instituto Mysterium, 2007.

CUNHA, Manuela Carneiro da. Cultura com aspas e outros ensaios. São Paulo: Cosac Naify, 2009.

DULLO, Eduardo; QUINTANILHA, Rafael. A sensibilidade secular da política brasileira. Debates do NER, Porto Alegre, v. 1, n. 27, p. 173-198, 2015.

GIUMBELLI, Emerson. A presença do religioso no espaço público: modalidades no Brasil. Religião \& Sociedade, Rio de Janeiro, v. 28, n. 2, p. 80-101, 2008.

GIUMBELLI, Emerson. Turismo religioso, gospel e políticas culturais: notas sobre articulaçôes entre religião e cultura no Brasil. In: REUNIÃO BRASILEIRA DE ANTROPOLOGIA, 29., 2014, Natal. Anais [...]. Natal: ABA, 2014. Disponível em: http://www.29rba.abant.org.br/resources/ anais/1/1401803505_ARQUIVO_ABA2014_textomesa.pdf. Acesso em: 29 nov. 2018.

HOWARD, Jay R.; STRECK, John M. Apostles of rock: the splintered world of contemporary Christian music. Kentucky: The University Press of Kentucky, 1999.

INGALLS, Monique. Awesome in this place: sound, space and identity in contemporary North American evangelical worship. 2008. Tese (Doutorado em Filosofia) - University of Pennsylvania, Philadelphia, 2008.

KELMAN, Ari. Shout to the Lord: making worship music in evangelical America. New York: New York University Press, 2018. 
MAFRA, Clara. A "arma da cultura" e os "universalismos parciais". Mana, Rio de Janeiro, v. 17, n. 3, p. 607-624, 2011.

MENDONÇA, Joêzer. Música e religiāo na era do pop. Curitiba: Editora Appris, 2014.

MILLER, Donald Earl. Reinventing American Protestantism: Christianity in the New Millennium. Los Angeles: University of California Press, 1997.

NEKOLA, Anna. "I'll take you there": the promise of transformation in the marketing worship media in US Christian music magazines. In: INGALLS, Monique; LANDAU, Carolyn; WAGNER, Tom (ed.). Christian congregational music: performance, identity and experience. Farnham: Ashgate, 2013. p. 117-136.

ORO, Ari Pedro; ALVES, Daniel. Encontros globais e confrontos culturais: o pentecostalismo brasileiro à conquista da Europa. DADOS: Revista de Ciências Sociais, Rio de Janeiro, v. 58, n. 4, p. 951-980, 2015.

ORO, Ari Pedro. Transnacionalização evangélica brasileira para Portugal: tipologia e acomodaçóes. Ciencias Sociales y Religión/Ciências Sociais e Religiäo, Porto Alegre, ano 19, n. 26, p. 14-51, set. 2017.

ROCHA, Cristina. A Megaigreja Hillsong no Brasil: a constituição de um campo religioso transnacional entre o Brasil e a Austrália. Plural: Revista do Programa de Pós-Graduaçáo em Sociologia da USP, São Paulo, v. 23, n. 2, p. 162-181, 2016.

ROSAS, Nina. Cultura evangélica e "dominaçāo" do Brasil: música, mídia e gênero no caso do Diante do Trono. 2015. Tese (Doutorado em Sociologia) - Universidade Federal de Minas Gerais, Belo Horizonte, 2015a.

ROSAS, Nina. "Dominaçáo" evangélica no Brasil: o caso do grupo musical Diante do Trono. Contemporânea, São Carlos, v. 5, n. 1, p. 235-258, 2015 b. 
SANT'ANA, Raquel. A música gospel e os usos da "arma da cultura": reflexôes sobre as implicaçôes de uma emenda. Revista Intratextos, Rio de Janeiro, v. 5, n. 1, p. 23-41, 2013.

WAGNER, C. Peter. Dominion: how kingdom action can change the world. Grand Rapids: Chosen Books, 2008.

Recebido em: 07/12/2018 Aprovado em: 13/06/2019 
